\title{
ALTRUISM, PATERNALISM AND TRANSFERS
}

\author{
Jérôme Ballet, Philippe Meral, Dawidson Razafimahatolotra*
}

\begin{abstract}
:
Discussions regarding the form that state transfers should take generally focus on the relative efficiency of transfers in kind vis-à-vis transfers in cash. This article, however, proposes a different approach - to determine the optimal structure of a donation, i.e. its optimal composition. Hence, the problem no longer lies in attempting to figure out whether a donation in kind is either more or less efficient than a donation in cash, but rather, to determine, through various hypotheses relative to the agent's behaviour, the most preferable structure for the donor.
\end{abstract}

Keywords: altruism, paternalism, transfer

JEL Classification: D 64

\section{Introduction}

Let us suppose that the Government decides to help its citizens ensure their well being, enhance their education or simply help them obtain sufficient amounts of food to survive. The question could be posed as follows: Is it preferable to supply them with assistance in kind directly (through health facilities, education/training and food), as well as indirectly (through subsidies on these goods and through vouchers), or is it preferable to provide them with a lump sum in cash that they could use to satisfy their needs?

According to the traditional model of the economics of well-being, transfers in cash would help obtain a Pareto-optimal situation, whereas transfers in kind would, in comparison, seem under-optimal.

This result led to numerous developments contesting the superiority of monetary transfers. Two of these arguments have played a crucial role. The first relates to an awareness of the donor's preferences and includes a reversing of the analysis of the beneficiary's preferences in favour of those of the donor. Within this context, as soon as one deals with the psychology or motives of the donor (Olsen, 1971a; Daly, Giertz, 1972), the superiority of monetary transfers no longer seems evident. Although transfers in kind do not permit the attainment of a Pareto optimum, they nevertheless permit us to attain a "paternalistic optimum" (Browning, 1981) that could be defined

* Jérôme Ballet, University of Versailles Saint Quentin en Yvelines, France (jballetfr@yahoo.fr); Philippe Meral, University of Versailles Saint Quentin en Yvelines, France; Dawidson Razafimahatolotra, University of Antananarivo, Madagascar. 
as the optimum which satisfies the preferences of the donors but which ignores those of the beneficiaries.

The second argument follows the same reasoning as the Samaritan's dilemma as presented by Buchanan (1975) and refers to the imperfection of information, especially regarding the amount of information available to the donor. If information on preferences were not publicly available to the donor - which is the Government the superiority of monetary transfers over those in kind would disappear (Diamond, Mirrlees, 1978; Dye, Antle, 1986; Harris, Townsend, 1981; Nichols, Zeckhauser, 1982; Roberts, 1984; Toumanoff, 1986; Blackorby, Donaldson, 1988). Indeed, this could result from the fact that certain individuals would try to claim transfers originally meant for others. If, for instance, the Government decides to compensate those who have been assaulted, it would not be surprising to observe that everyone would then declare himself a victim of assault. Hence, as long as the Government is unable to differentiate between true and false victims, between those who are in real need and the rest of the population, it would no doubt be advantageous to carry out transfers in kind rather than in cash. The question thus becomes one of excluding the fake needy (Jones, Cullis, 1997).

These arguments, however, focus on the sole question of the comparative efficiency of transfers in cash and in kind. However, as Garfinkel notes (1973), if the donor gains satisfaction from both the amount and nature of the beneficiary's consumption, the optimal solution would then consist in a combination of transfers in cash and kind. We shall base ourselves on this second problematic. We shall hence not attempt to discuss the comparative efficiency of various forms of transfers, but rather, shall propose a new dimension to the question through the optimal transfer structure of the donor.

This article introduces three new methodological aspects insofar as Garfinkel's model is concerned. Firstly, it introduces the parameter of altruism into the donor's preference function. Secondly, the form of the gift cash or kind also determines donor's preferences. We shall make use of the parameter of paternalism to rewrite such preference. Thirdly, we will introduce the parameter of preference of beneficiary vis-à-vis the gift. But most importantly, one should bear in mind that the donor evaluates his preference regarding the beneficiary and takes this into account when optimizing his act.

The article shall be structured in the following manner. The following section presents the general model and deduces the first results. The third section focuses on the behaviour and choices of the donor. It permits us to characterize an optimal position for the donor. The fourth section proposes complementary results based on a specified utility function. It illustrates the notion of the gift's optimal structure.

\section{Presentation of the Model}

Let us suppose there are two individuals, one an altruistic donor 1 , and the other, the beneficiary of the donor's transfers, 2 .

They both possess an initial amount of resources permitting them to consume a unique basket of goods at a unitary price, which would give us the following notations:

$C_{i}:$ i's consumption and

$R_{i}^{i}:$ the initial resource or endowment of $\mathrm{i}$.

$E$ : Proportion of resource held by 2 in relation to 1 . 
The philosophy of this model is based upon an altruistic relation between the donor, agent 1 , and the beneficiary, agent 2 . One must then distinguish between that which is relative to the maximization of the intrinsic utility for each agent, presented as $U_{i}$, and the altruistic utility, presented as $V_{i}$.

The utility of 1 and 2 could thus be defined as:

$$
\begin{gathered}
U_{1}=U\left(C_{1}\right) \text { and } U_{2}=U\left(C_{2}\right) \\
\text { s.t. } U \text { ' }>0 \text { and } U "<0 .
\end{gathered}
$$

$C_{1}$ and $C_{2}$ are the consumption of 1 and 2 .

The donor is considered as altruistic. The term altruistic refers to 1 's predisposition to renounce part of his resources in favor of another individual. 1's utility function could then be presented as follows:

$$
V_{1}=U_{1}+\alpha V_{2}+\delta U(N)
$$

Wherein $\alpha$ refers to the 1 's degree of altruism with reference to $2 . V_{2}$ is the utility function of 2 taking into account by 1 upon completion of the transfer. It could thus be presented as :

$$
V_{2}=U_{2}+(1-\varepsilon) U(N)
$$

Our model presupposes that the beneficiary is not altruistic towards the donor. In other words, the beneficiary does not express his gratitude to the donor. This corresponds well to cases such as those where the donor is a government seeking to help the most deprived.

Beyond $\alpha$, our model highlights two major factors: $\delta$ and $\varepsilon$.

$\delta$ is a parameter of paternalism. Paternalism could be defined as 1 's sensitivity to the form of the transfer, cash or kind. It could thus be interpreted as the donor's sensitivity to the valorization of his gift. According to the structure of the relations, every paternalist $0<\delta<1$ is altruistic. However, it is equally possible to be altruistic without being paternalistic. If $\delta=0$, then, donor 1 would let 2 choose the use of the donation for himself. In such an event, the structure of the donation would favour a donation in cash, in conformity with the principle of consumer sovereignty. On the other hand, if $0<\delta<1,1$ would then express sensitivity to the structure of the choice, and, in this case, the donation would be in favour of a donation in kind.

Meanwhile, parameter $\varepsilon$ represents the beneficiary's sensitivity towards the dona/ tion, or, more specifically, his preference to donations in kind. Thus, as the value of $\varepsilon$ becomes greater, the depreciation of donations in kind becomes more important for the beneficiary, which could in turn be translated as an increased preference for donations in cash. Parameter $\varepsilon$ thus implies that a donation in kind does not necessarily have the same value as a donation in cash insofar as the beneficiary is concerned. The depreciation attached to donations in kind can be regarded as depreciation felt by the beneficiary upon reception of a donation in kind. This depreciation results in the restriction of his choice over consumption. It can even represent the stigmatization that donations in kind could have on the beneficiary (Ballet and Razafimahatolotra 2004). Meanwhile, in our model $\varepsilon$ is interpreted as disutility for the beneficiary perceived from the donor point of view. 
As such, if the parameter $\alpha$ represents altruism, $\delta$ and $\varepsilon$ represent the donor's paternalism and the consumer's sovereignty respectively. Models would traditionally use one or the other to depict the existence of a paternalistic optimum or of the consumer's sovereignty. However, focus shall be laid, in this article, upon the coexistence of the two in a model, where $\alpha$ plays a specific role.

1 's altruistic utility could thus be defined as

$$
V_{1}=U\left(C_{1}\right)+\alpha U\left(C_{2}\right)+(1-\varepsilon+\delta) U(N)
$$

budgetary constraints are

$$
R_{1}-T=C_{1} \text { and } E R_{1}+T-N=C_{2}
$$

where $\mathrm{T}$ and $\mathrm{N}$ represent the total transfer and the volume of the transfer in kind respectively.

We suppose that $R_{1}=1$, the resolution of this maximization problem gives us:

$$
\begin{gathered}
V_{1}=U(1-T)+\alpha U(E+T-N)+(1-\varepsilon+\delta) U(N) \\
V_{1}=(1-\alpha) \ln (2-M-N)+\alpha \ln (1+E+M)+(1-\varepsilon+\delta) \ln (1+N)
\end{gathered}
$$

Optimizing $V_{1}$ in function of $T$ and $M$, we have the following propositions :

\section{Proposition 1}

a) The volume of donation is an increasing function of the donor's altruism

$$
\frac{\partial T}{\partial \alpha} \geq 0
$$

b) Donation in kind is negatively correlated with the donor's altruism

$$
\frac{\partial N}{\partial \alpha} \leq 0
$$

c) The volume of donation is positively correlated with the paternalism of the donor

$$
\frac{\partial T}{\partial \delta} \geq 0
$$

d) Donation in kind is positively correlated with the paternalism of the donor

$$
\frac{\partial N}{\partial \delta} \geq 0
$$

e) The volume of donation is a decreasing function of the proportion of resource $E$

$$
\frac{\partial T}{\partial E} \leq 0
$$

f) Donation in kind is positively correlated with the proportion of resource $E$

Proof: see Annex 1

$$
\frac{\partial N}{\partial E} \geq 0
$$


Our model conceives symmetry between the depreciation attached to in kind transfer by the beneficiary and utility of this transfer for the donor. In that sense, $\delta$ and $\varepsilon$ have opposite effects.

Proposition 1 gives us directional effects of the actors behaviour. The next proposition concerns intensities of variation. Based on these intensities, we may develop the idea of efficient structure of the gift.

\section{Proposition 2}

a) Marginal effect of paternalism on transfer in kind is stronger than its marginal effect on the volume of the gift.

b) If we suppose that 1 's choice to assist 2 includes a certain degree of risk, then $-\frac{u^{\prime}(N)}{u^{\prime \prime}(N)}$ measures the paternalistic donor's risk aversion. As such, marginal effect of paternalism is increased by donor's risk aversion.

$$
\frac{\partial T}{\partial \delta}<\frac{\partial N}{\partial \delta}<-\frac{u^{\prime}(N)}{u^{\prime \prime}(N)}
$$

Proposition $2 b$ indicates that paternalistic donor is very sensitive to the risk. If the donor anticipates its in kind transfer induce a strong depreciation for the beneficiary, i.e. its risk degree is high, then paternalism has a weak effect on the gift.

c) Altruism is less sensitive than paternalism to the risk.

Marginal effects of altruism are given by the following relation:

$$
\left|\frac{\partial N}{\partial \alpha}\right|<\min \left(-\frac{1}{\alpha} \frac{u^{\prime}(N)}{u^{\prime \prime}(N)}, \frac{1}{1-\varepsilon+\delta} \frac{\partial T}{\partial \alpha}\right)
$$

As $0<\alpha<1$, the first inequality $\left|\frac{\partial N}{\partial \alpha}\right|<-\frac{1}{\alpha} \frac{u^{\prime}(N)}{u^{\prime \prime}(N)}$ reflects the proposition 2c. In another way, in kind transfer is more sensitive to risk anticipation than transfer in cash. Proof: see Annex 2.

\section{Altruism - Paternal Behaviour and Choices}

The two propositions that were formulated in the preceding section give us a certain idea about parameters. However, they do not permit us to define an optimal position for the donor. For example, the first assertion in proposition 1 indicates that different values of $\alpha$ gives different altruistic positions. Then, for $\alpha_{1}>\alpha_{2}$, the total donation with $\alpha_{1}$ is greater than with $\alpha_{2}$. Nevertheless, the position obtained with $\alpha_{1}$ is not necessarily better than the position obtained with $\alpha_{2}$.

In contrary to Walrasian representation that deals to a unique solution, our model focuses on multiple optimal choices. The benevolent dictator i.e. the paternalistic donor gives the social choice. 
In order to characterize the optimal structure of donation, let us define donation efficiency by the following function:

$$
\xi_{\varepsilon}(N, M)=\frac{1}{1+\varepsilon} \frac{U\left(C_{2}+M\right)+(1-\varepsilon) U(N)-U(T)}{U\left(C_{1}\right)-U\left(C_{1}-T\right)}
$$

In this definition, the numerator measures difference between utility of the transfer for the beneficiary and for the donor. If this difference is negative, then the donor obtains a greater utility than the beneficiary. The denominator measures the loss of welfare or the donor sacrifice. $\frac{1}{1+\varepsilon}$ represents disutility effect on donation's efficiency.

This definition helps us identify the optimal structure of a donation as seen from the angle of efficiency for the donor. This implies that the donor compares what he could gain through his donation to what he has to sacrifice in making this gift.

Using this definition, we obtain the main result in the following theorem:

\section{Theorem}

There is $l \in I R^{+}$satisfying

$\forall a \in[0, l]$, there exists an optimal position which its efficiency is exactly a.

\section{Corollary}

If $\varepsilon, \delta, E$ are given, then there is a value of $\alpha, \alpha_{\text {ope }}$ ensuring to the donor 1 an efficient position.

\section{Remark}

The donation efficiency decreases with ratio $E$.

Proof: See Annex 3

This theorem shows us the donor may achieve a maximal efficient level for its gift: $l$. Propositions 1 and 2 give us information about transfer possibilities. The theorem proves the existence of an optimal position. Whatever be the level of donation, the theorem implies that an optimal position is always feasible. Corollary tell us that, knowing parameters $\varepsilon, \delta$, and $E$, the donor may achieve an optimal position ensuring donation's efficiency.

Within the framework of our analysis, an optimal position is an optimal structure of the gift from the donor's point of view. This theorem proves the existence of an optimal position, but does not offer an illustration of the structure of this optimal donation. The following section proposes some illustrations from specific functions. 


\section{Simulations and Illustrations}

Let $u(x)=\sqrt{x}$. We have for all $x \in[0,1]: u \geq 0, u^{\prime}>0$ and $u^{\prime \prime}>0$.

The utility function of the donor can be written as

$$
V_{1}=\sqrt{1-T}+\alpha \sqrt{E+T-N}+(1-\varepsilon-\delta) \sqrt{N}
$$

The solutions of first's order equations are :

$$
\begin{gathered}
N_{E}(\alpha, \delta, \varepsilon)=\frac{(E+1)(1-\varepsilon+\delta)^{2}}{2-2 \varepsilon+2 \delta+\varepsilon^{2}-2 \varepsilon \delta+\delta^{2}+\alpha^{2}} \\
T_{E}(\alpha, \delta, \varepsilon)=\frac{1-2 \varepsilon+2 \delta+\varepsilon^{2}-2 \varepsilon \delta+\delta^{2}+\alpha^{2}-E}{2-2 \varepsilon+2 \delta+\varepsilon^{2}-2 \varepsilon \delta+\delta^{2}+\alpha^{2}}
\end{gathered}
$$

\section{Remarks on equations (8) and (9)}

Solutions are at their maximum since the Jacobian is strictly negative.

$\mathrm{N}=0$ if and only if $\varepsilon=1$ and $\delta=0$. In this case, the depreciation of the transfer in kind is maximal and the paternalistic degree is minimal. In the others cases, $N \in] 0,1[$ $T \in] 0,1[$ for all $\alpha, \delta, \varepsilon, E$.

These remarks imply that the volume of transfers is not greater than the endowment of the donor. Also, we postulate that the total transfer is higher than the transfer in kind. This assumption excludes incoherent values of parameters for computations.

From equations (7), (8) and (9) we have the following results:

Firstly, result 1 illustrates conditions of feasibility for donation. Secondly, result 2 shows donation structure and, thirdly, result 3 represents efficient position for the donor.

\section{Result 1. Conditions of feasibility for donation}

\section{Assertion 1}

There is $\alpha_{\min }$ such that for all $\alpha \leq \alpha_{\min }$ the transfer is not feasible or has no sense.

After computation, $\alpha_{\min }=\sqrt{E\left(2-2 \varepsilon+2 \delta+\varepsilon^{2}-2 \varepsilon \delta+\delta^{2}\right)}$

and Corollary

$$
\begin{gathered}
\lim _{E \rightarrow 0} \alpha_{\min }=0, \\
\lim _{E \rightarrow 1} \alpha_{\min }=\sqrt{1+(1-\varepsilon+\delta)^{2}} \geq 1, \\
\lim _{\varepsilon \rightarrow 1} \alpha_{\text {min }}=\sqrt{E\left(1+\delta^{2}\right)}
\end{gathered}
$$

If the beneficiary is very poor, there is no minimal altruism. On the contrary, if the beneficiary has the same endowment that the donor, the latter cannot take a altruistic position excepted if he is sacrificial, $\lim _{E \rightarrow 1} \alpha_{\min } \geq 1$. The third limit concerns relation between depreciation parameter and altruism. If depreciation parameter is very high, minimal altruism tend to attend a high level, close to 1 , i.e. the donor must also be sacrificial. 
Let us take $\delta=\varepsilon$, the following graph 1 illustrates result 1, i.e. the value of $\alpha_{\min }$ for different values of $E$. The first axis represents $\mathrm{E}$, the second $\delta$ and the vertical axis values of $\alpha_{\min }$. On this graph, a value $\alpha_{\min }=1$ is obtained for $\mathrm{E} \approx 40 \%$.

\section{Graph 1}

Illustration of Assertion 1, Result 1

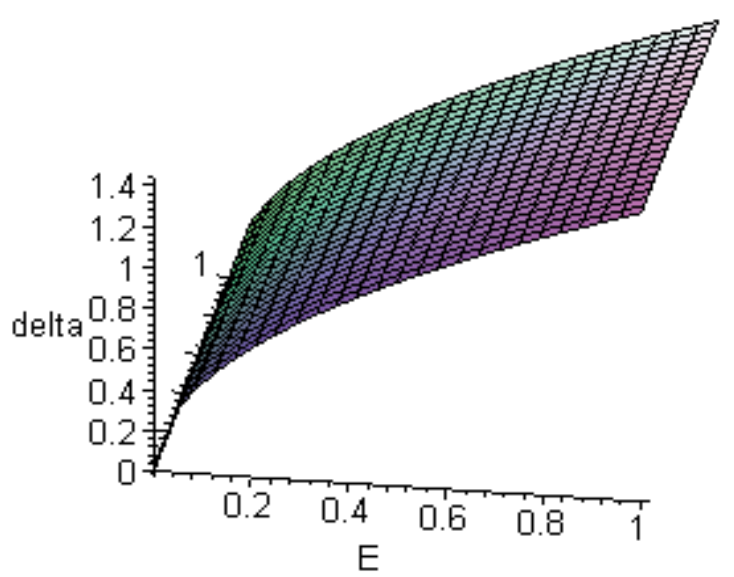

The first assertion is equivalent to:

\section{Assertion 2}

There is a maximal value of ratio $E_{\max }$ s.t if $E \geq E_{\max }$, any transfer is done. $E_{\max }$ indicates that donor does not accept to aid a beneficiary considered by him as sufficiently rich, i.e. someone who do not need his benevolence.

$$
E_{\text {max }}=\frac{\alpha^{2}}{\varepsilon^{2}+\delta^{2}+2(1-\varepsilon+\delta-\varepsilon \delta)}
$$

The preceding equation shows that $E_{\max }$ increase with $\alpha$. Then $\alpha$ represents the do/ nor's tolerance. More a donor is tolerant more he accepts to aid someone with high endowment.

After computing first derivation of $E_{\max }$, we have $\frac{\partial E_{\max }}{\partial \delta} \leq 0$. More the donor is paternalistic less he accepts to transfer to a rich beneficiary.

The following Graph 2 shows variation of $E_{\max }$ with $\alpha$ and $\delta$, where $\varepsilon$ takes a reasonable value, $\varepsilon=25 \%$. 


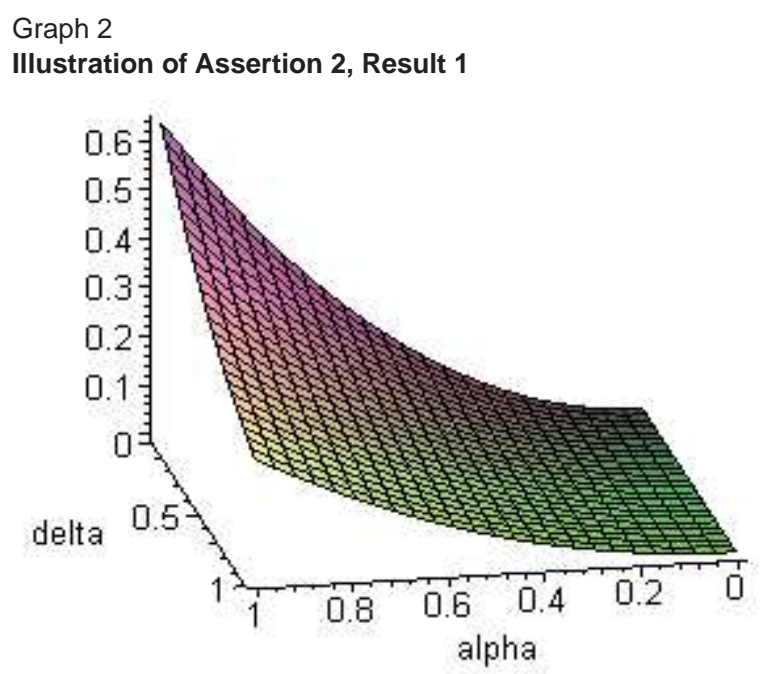

Result 1 gives conditions of feasibility for the donation. Result 2 illustrates the donation structure.

\section{Result 2. Donation structure}

Let us now define $S=\frac{N}{N+T}$.

For our simulation, the expression of $S$ in percentage is given by:

$$
S_{\alpha, \delta, \varepsilon, E}=100 \frac{(E+1)(1-\varepsilon+\delta)^{2}}{1-2 \varepsilon+2 \delta+\varepsilon^{2}-2 \delta \varepsilon+\delta^{2}+\alpha^{2}-E}
$$

Assertion 1

$$
\frac{\partial S}{\partial E} \geq 0 \text { and } \frac{\partial S}{\partial \alpha} \leq 0
$$

In kind transfer is positively dependant to parameter $E$ whereas cash transfer is positively dependant to the altruistic parameter. For a moderate value of $\delta, \delta=0,2$ and for reasonable value of $\varepsilon, \varepsilon=25 \%$, we have the following Graph 3 . 


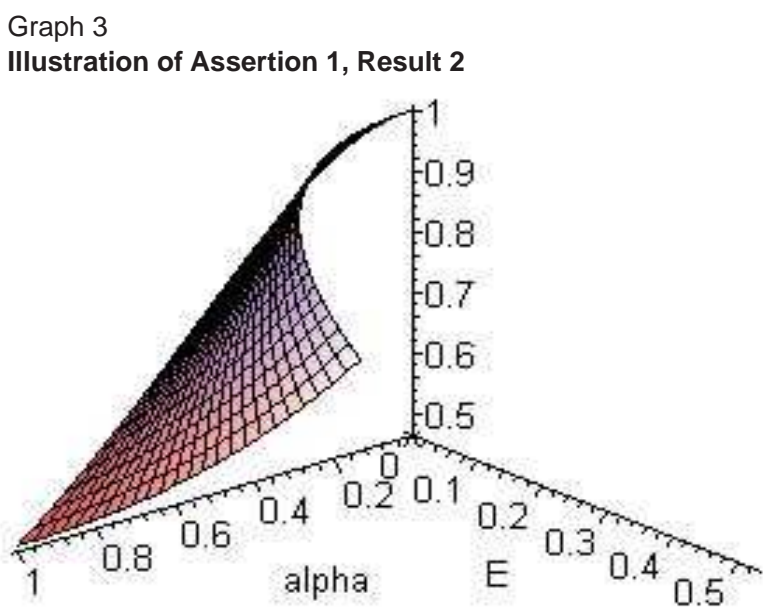

Assertion 2

$\frac{\partial S}{\partial \delta}=0$ if $\alpha^{2}=E$. If $E \geq \alpha^{2}$ then $\frac{\partial S}{\partial \delta} \leq 0$ and if $E \leq \alpha^{2}, \frac{\partial S}{\partial \delta} \geq 0$.

Knowing that $\alpha_{\text {min }}^{2} \geq E$, then $\frac{\partial S}{\partial \delta} \geq 0$.

The following Graph 4 shows evolution of proportion of in kind transfers with $\delta$ and $E$, if $\alpha$ takes the moderate value $\alpha=0.25$ and $\varepsilon=25 \%$. We observe that the maximal value of $\mathrm{E}$ is $E \approx 4 \%$

Graph 4

Illustration of Assertion 2, Result 2

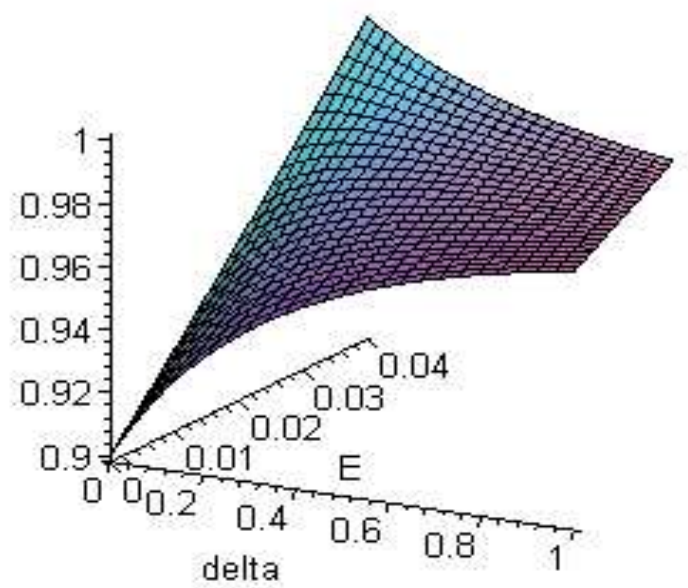




\section{Result 3 Efficient position}

\section{Assertion 1}

The altruistic optimal position $\alpha_{\text {opt }}$ is s.t $\alpha_{\text {opt }} \geq \alpha_{\min }$ and $\lim _{\varepsilon \rightarrow 1} \alpha_{o p t}-\alpha_{\min }=0$ where other parameters take their saturation values.

This result ensure that the optimal position is better than the minimal altruism i.e. the optimal position is not necessary a prudential altruism $\left(\alpha_{\min }\right)$. However, if $\varepsilon \rightarrow 1$, the disutility of the gift is high, then $\alpha_{\text {opt }} \approx \alpha_{\min }$ and prudence is an optimal altruistic position.

The expression of derivatives of the efficiency function is very complex. We only show few results on efficiency in the following table.

Table 1

Efficiency Results

\begin{tabular}{|c|c|c|c|c|c|}
\hline \multicolumn{3}{|c|}{ Others parameters } & $\alpha_{\text {opt }}$ & $\alpha_{\min }$ & Comments \\
\hline$E=0$ & \multirow{2}{*}{$\delta=0$} & \multirow{2}{*}{$\varepsilon=0$} & 0.5 & 0 & \\
\hline$E=1$ & & & 0 & 0 & \\
\hline$E=0$ & \multirow{3}{*}{$\delta=0.05$} & \multirow{3}{*}{$\varepsilon=0.05$} & 0.5 & 0.3 & \multirow{3}{*}{$\begin{array}{l}\text { For E from } 0 \text { to } 0.19, \alpha_{o p t} \text { is increasing } \\
\text { and from } 0.19 \text { to } 0.75826 \alpha_{o p t} \\
\text { decrease. Others cases are not } \\
\text { interesting because } \alpha_{\text {opt }}<\alpha_{\min }\end{array}$} \\
\hline$E=0.19$ & & & 0.616 & 0.339 & \\
\hline \multirow[t]{4}{*}{$E=0.75826$} & & & 0.442 & 0.442 & \\
\hline & $\delta=0.566$ & $\varepsilon=0.05$ & 0.999 & 0.256 & \multirow{3}{*}{$\begin{array}{l}\text { For a given } E \text {, if the depreciation of the } \\
\text { donation increase then the paternalistic } \\
\text { position relative to the optimal altruistic } \\
\text { position decrease. By symmetry, } \\
\text { if we have fixed } \delta \text {, the optimal } \\
\text { altruistic position is decreasing with } \varepsilon .\end{array}$} \\
\hline & $\delta=0.535$ & $\varepsilon=0.25$ & 0.999 & 0.574 & \\
\hline & $\delta=0.5$ & $\varepsilon=0.5$ & 0.999 & 0.824 & \\
\hline
\end{tabular}

\section{Conclusion}

The debate on the composition of transfers, their proportion in cash and kind, is based on the efficiency relative to the different forms. The model developed in this article examines a different topic. It is aimed at finding out what is the optimal structure of donations for a paternalistic donor, taking into consideration the behaviour models of both donor and beneficiary.

The model developed herein establishes the proportion of the donation in kind and consequently, its proportion in cash. This model examines not only the very question of the existence and volume of donations, but also the elements that influence their structure. As such, if altruism has any influence upon these structures, it is no doubt the donor's degree of paternalism and the degree of the beneficiary's disutility with regard to donations in kind that primarily affect these structures. 


\section{References}

Ballet, J., Razafimahatolotra, D., 2004, Don et stigmatisation. mimeo, University of Versailles saint Quentin.

Blackorby, C., Donaldson, D., 1988. Cash versus Kind, Self Selection and Efficient Transfers, American Economic Review 78(4), pp. 691-700.

Browning, E. K., 1981, A Theory of Paternalistic In-Kind Transfers, Economic Inquiry 19, pp. 579-597.

Bruce, N., Waldman, N., 1991, Transfers in Kind : Why They Can Be Efficient and Nonpaternalistic, American Economic Review 81(5), pp. 1345-1351.

Buchanan, J., 1975, The Samaritan's Dilemma. In: Phelps, E. S. (ed), Altruism, Morality and Economic Theory, New York, Russel Sage Foundation, pp. 71-85.

Coate, S., 1995, Altruism, the Samaritan's Dilemma, and Government Transfer Policy, American Economic Review 85(1), pp. 46-57.

Daly, G., Giertz, J., 1972, Welfare Economics and Welfare Reform, American Economic Review 62, pp. 131-138.

Daly, G., Giertz, J., 1976, Transfers and Pareto Optimality, Journal of Public Economics 5, pp. 179-192.

Diamond, P. A.; Mirrlees, J., 1978, A Model of Social Insurance with Variable Retirement, Journal of Public Economics 10, pp. 295-336.

Dye, R. A.; Antle, R., 1986, Cost-Minimizing Welfare Programs, Journal of Public Economics 30 pp. 259-265.

Foldes, L. P., 1967a, Income Redistribution in Money and Kind, Economica 34, pp. 30-41.

Foldes, L. P., 1967b, A Note on Redistribution, Economica 34, pp. 203-205.

Foldes, L. P., 1968, Redistribution: a Reply, Economica 35, pp. 198-204.

Friedman, M., 1962, Capitalism and Freedom. Chicago: Chicago University Press.

Garfinkel, I., 1973, Is In-Kind Redistribution Efficient? Quarterly Journal of Economics 87, pp. 320-330.

Hausman, D. M., Mc Pherson, M. S., 1996, Economic Analysis and Moral Philosophy. Cambridge: Cambridge Universtity Press.

Harris, M., Townsend, R., 1981, Resource Allocation Under Asymmetric Information, Econometrica 49, pp. 33-64.

Jones, P. R., Cullis, J. G., 1997, In-Kind versus Cash Transfers: Assessing Disbursement, Public Finance Review 25(1), pp. 25-43

Nichols, A. L., Zeckhauser, R. J., 1982, Targeting Transfers through Restrictions on Recipients, American Economic Review, Papers and Proceedings 72, pp. 372-377.

Okun, A., 1975, Efficacité versus Equité. Paris: Economica.

Olsen, E. O., 1969, A Competitive Theory of the Housing Market, American Economic Review, pp. 612-622.

Olsen, E. O., 1971a, Subsidized Housing in a Competitive Market : Reply, American Economic Review, pp. 220-224.

Olsen, E. O., 1971b, Some Theorems in the Theory of Efficient Transfers, Journal of Political Economy, 1971, pp. 166-176.

Pauly, M. V., Danzon, P., Feldstein, P., Hoff, J., 1991. A Plan for Responsible National Health Insurance, Health Affairs 10 (2), pp. 5-25.

Roberts, K., 1984, The Theoretical Limits to Redistribution, Review of Economic Studies 51, pp. 177-195.

Summers, L. H., 1989, Some Simple Economics of Mandated Benefits, American Economic Review, Papers and Proceedings 79(2), pp. 177-83.

Thurow, L. C., 1971, The Income Distribution as a Pure Public Good, Quarterly Journal of Economics 85(2), pp. 327-336.

Thurow, L. C., 1974. Cash versus In-Kind Transfers, American Economic Review 190-195.

Toumanoff, P., 1986. Exclusion Costs and the In-Kind Transfer, Kyklos, 39(3), pp. 443-447. 


\section{Annex 1}

\section{Proposition $1 a$ and $1 b$}

Optimization of $V_{1}$ by $T$ and $N$ gives,

$$
\begin{gathered}
-u^{\prime}(1-T)+\alpha u^{\prime}(E+T-N)=0 \\
-\alpha u^{\prime}(E+T-N)+(1-\varepsilon+\delta) u^{\prime}(N)=0
\end{gathered}
$$

These two equations involve:

$$
\begin{aligned}
& (1-\varepsilon+\delta) u^{\prime}(N)=u^{\prime}(1-T) \\
& \alpha u^{\prime}(E+T-N)=u^{\prime}(1-T)
\end{aligned}
$$

Differentiating by $\alpha$,

$$
\begin{gathered}
(1-\varepsilon+\delta) \frac{u^{\prime \prime}(N)}{u^{\prime \prime}(1-T)}=-\frac{\partial T}{\partial \alpha} / \frac{\partial N}{\partial \alpha} \\
\frac{\partial T}{\partial \alpha}\left(\alpha u^{\prime \prime}(E+T-N)+u^{\prime \prime}(1-T)\right)-\alpha u^{\prime \prime}(E+T-N) \frac{\partial N}{\partial \alpha}+u^{\prime}(E+T-N)=0
\end{gathered}
$$

Hypothesis $u^{\prime}>0$ and $u^{\prime \prime}<0$ with (5) give

$$
\frac{\partial T}{\partial \alpha} / \frac{\partial N}{\partial \alpha} \leq 0
$$

Now, prove by absurdity that $\frac{\partial T}{\partial \alpha} \geq 0$

Suppose that $\frac{\partial T}{\partial \alpha}<0$, we obtain $\frac{\partial N}{\partial \alpha} \geq 0$. Knowing that $u^{\prime}>0$ and $u^{\prime \prime}<0$,

$$
\frac{\partial T}{\partial \alpha}\left(\alpha u^{\prime \prime}(E+T-N)+u^{\prime \prime}(1-T)\right)-\alpha u^{\prime \prime}(E+T-N) \frac{\partial N}{\partial \alpha}+u^{\prime}(E+T-N)>0
$$

It is in contradiction with (6) i.e $\frac{\partial T}{\partial \alpha} \geq 0$ and also $\frac{\partial N}{\partial \alpha} \leq 0$.

\section{Proposition 1c and 1d}

Differentiating (3) and (4) by $\delta$, 


$$
\begin{gathered}
u^{\prime}(N)+u^{\prime \prime}(N) \frac{\partial N}{\partial \delta}+u^{\prime \prime}(1-T) \frac{\partial T}{\partial \delta}=0 \\
\alpha u^{\prime \prime}(E+T-N)\left(-\frac{\partial N}{\partial \delta}+\frac{\partial T}{\partial \delta}\right)+u^{\prime \prime}(1-T) \frac{\partial T}{\partial \delta}=0
\end{gathered}
$$

Multiply (8) by $\frac{\partial T}{\partial \delta}$, we obtain $\frac{\partial T}{\partial \alpha} / \frac{\partial N}{\partial \alpha} \geq 0$

Moreover, if we suppose that $\frac{\partial T}{\partial \delta}<0,(7)$ leads us to an absurdity.

$$
\text { Also } \frac{\partial T}{\partial \delta} \geq 0 \text { and } \frac{\partial N}{\partial \delta} \geq 0
$$

\section{Proposition 1e anf $1 f$}

By (3),

$$
(1-\varepsilon+\delta) u^{\prime \prime}(N) \frac{\partial N}{\partial E}=-u^{\prime \prime}(1-T) \frac{\partial T}{\partial E}
$$

i.e.

$$
\frac{\partial N}{\partial E} \frac{\partial T}{\partial E} \leq 0
$$

and by (4)

$$
\alpha u^{\prime \prime}(E+T-N)\left(1+\frac{\partial T}{\partial E}-\frac{\partial N}{\partial E}\right)=-u^{\prime \prime}(1-T) \frac{\partial T}{\partial E}
$$

So

$\operatorname{sig}\left(1+\frac{\partial T}{\partial E}-\frac{\partial N}{\partial E}\right)=-\operatorname{sig}\left(\frac{\partial T}{\partial E}\right)$

If $\frac{\partial T}{\partial E}>0$, then $0<1+\frac{\partial T}{\partial E} \leq \frac{\partial N}{\partial E}$ i.e $\frac{\partial N}{\partial E} \frac{\partial T}{\partial E}>0$. It is in contradiction with (9).

Also,

$\frac{\partial T}{\partial E} \leq 0$ and $\frac{\partial N}{\partial E} \geq 0$ 


\section{Annex 2}

\section{Proposition 2a}

By (8), we can write

$$
\frac{\partial T}{\partial \delta}=\frac{\partial N}{\partial \delta} \frac{\alpha u^{\prime \prime}(E+T-N)}{\alpha u^{\prime \prime}(E+T-N)+u^{\prime \prime}(1-T)}
$$

Now that $u^{\prime \prime}<0$, then

$$
\frac{\partial T}{\partial \delta} \leq \frac{\partial N}{\partial \delta}
$$

\section{Proposition $2 b$}

Equation (7) with (5) imply

$$
\frac{u^{\prime}(N)}{u^{\prime \prime}(N)} \frac{1}{\partial N / \partial \delta}+1-(1-\varepsilon+\delta) \frac{\partial T / \partial \delta}{\partial T / \partial \alpha} \frac{\partial N / \partial \delta}{\partial N / \partial \alpha}=0
$$

By proposition 1,

$$
(1-\varepsilon+\delta) \frac{\partial T / \partial \delta}{\partial T / \partial \alpha} \frac{\partial N / \partial \delta}{\partial N / \partial \alpha} \leq 0
$$

Then by (9), we have $\frac{u^{\prime}(N)}{u^{\prime \prime}(N)} \frac{1}{\partial N / \partial \delta} \leq-1$. So

Proposition 2c

$$
\frac{\partial N}{\partial \delta} \leq-\frac{u^{\prime}(N)}{u^{\prime \prime}(N)}
$$

we can get proposition $2 \mathrm{~b}$ and $2 \mathrm{c}$ in the same way. 


\section{Annex 3}

\section{Theorem}

Denote

$$
\xi_{\varepsilon}(N, M)=\frac{1}{1+\varepsilon} \frac{u\left(C_{2}+M\right)+(1-\varepsilon) u(N)-u\left(C_{2}\right)}{u\left(C_{1}\right)-u\left(C_{1}-N-M\right)}
$$

Because $u(0)=0$ and $N, M \leq N+M$, then we have $\lim _{M+N \rightarrow 0} \xi=0$

In addition, $\xi_{\varepsilon}:[0, T]^{2} \rightarrow[0,1]^{2}$ is continue and $[0,1]^{2}$ is compact, then $\xi_{\varepsilon}$ is bonded and there is a point in which it takes his maximum value, say $\boldsymbol{l}$.

Now, let $a \in[0, l]$ and write

$\chi_{a}\left(C_{i}, N, M\right)=u\left(C_{2}+M\right)+(1-\varepsilon) u(N)-u\left(C_{2}\right)-a(1+\varepsilon)\left(u\left(C_{1}\right)-u\left(C_{1}\right)-N-M\right)$

$\chi_{a}$ is twice differentiable and his Jacobian in $(C, N, M)$ is different of 0 , then there exist a position which efficiency is exactly $a$.

\section{Remark}

Let us write $\xi_{\varepsilon}(N, M)=\frac{1}{1+\varepsilon} \frac{\Delta u_{2}}{\Delta u_{1}}$ $\frac{\partial T}{\partial E} \leq 0$ then $\frac{\partial \Delta u_{1}}{\partial E} \leq 0$. Therefore, $\operatorname{sig}\left(\xi_{\varepsilon}\right)=-\operatorname{sig}\left(\frac{\partial \Delta u_{2}}{\partial \delta}\right)$.

Now, $\frac{\partial \Delta u_{2}}{\partial E}=u^{\prime}(E+T-N)\left(1+\frac{\partial T}{\partial E}-\frac{\partial N}{\partial E}\right)+(1-\varepsilon) u^{\prime}(N) \frac{\partial N}{\partial E}$,

Then by (9) proposition $1, \frac{\partial \Delta u_{2}}{\partial E} \geq 0$

So we conclude that $\frac{\partial \xi_{\mathcal{E}}}{\partial E} \leq 0$ 